\title{
General Environment Of World
}

\author{
By
}

Dr. Mohammed Viquaruddin ${ }^{1}$

\begin{abstract}
This paper is an attempt regarding the general social/economical/ecological/ political and more environments of world certainly with multidisciplinary/ interdisciplinary approach. It is discussed that the problems of fore further can be solved through facts/reasoning/science/environment/social sciences etc. As being a student of political science even peace science a try that can come into existence or can be practiced only through many dimensions. The philosophy is developed to resist with whatever means we have in hand and are willing to fight for a better scenario which would be something out of our reach! But can achieve through a positive and plural system not certainly perfect but different in its approach. Achievement to the threats and problems to the liberal vision are pervasive and the system is in much greater problematic that is commonly supposed. Protecting/ Preserving/ Commanding it in the coming century and beyond will be easier said than done? We do not foresee the renaissance of any type we should be sure about that alternative World Multidimensional System (WMS) could reasonably compete with the present multidimensional system on theoretical or practical grounds. It is not enough that this system display substantial practical advantages and genuine theoretical coherence. No one can deny that world get profit from present system.
\end{abstract}

Key Words: development, peace, culture, social structure, health.

\section{Background:}

The development, so bravely launched in the early 1960's, is ending in growing frustration. Movements for cooperation in the world seem to be stymied by the recalcitrance of De Gaulle and the different assessments and priorities of the West European states. The encouraging steps toward Asian and African unity are foundering on the rocks of personal and nationalistic rivalries, mounting atomic stockpiles in the arsenals of nuclear powers and the danger of further nuclear proliferation are grim reminders of the precariousness of the balance of 
terror and deterrence strategies on which the peace of the world seem to depend. Problem of race and color are clearly being accentuated. ${ }^{1}$

At the start of the twenty-first century Political science face worldwide important and common challenges. These are generally captured around the theme of globalization or internationalization leads queries that what will be the future of Political science? What would be the prospect of isms (Democracy, Communism, Monarchy, Dictatorship etc) and International politics that the globe observing? Can one find the answer(s) in the context of the present scenario of the world politics? It is therefore necessary to focus on a relatively less considered issue of social pluralism in Political science. The present political trends are offshoot of past development in political process as well system.

As we enter this Century, one of the most disturbing facts is that the military expenditures around the world are on the increase. And the century we left behind, William Shirer described, "Gone are those pleasant nineteenth century days when a country could remain neutral and at peace just by saying it wanted to". ${ }^{2}$ In the mid 1990 s, the known military expenditure was US $\$ 800$ billion each year, or $\$ 145$ per person worldwide, which has significantly increased due to expanding conflicts in various parts of the world. Almost half the world's scientists and engineers are said to be involved in military R\&D. imagine if this cadre of experts could be brought to work for peace. Had there been global peace, during the same period, by the year 2002, the accumulated total in saving or what is termed peace dividends, could have been about $\$ 1,600$ billion that obviously increases today, which could have been diverted to promote human development on a massive scale never imagined before. The harsh reality is that while the current century has been heralded as a time for peace, today we are in a world thriving in a culture of violence. "On Sep $11 \ldots$ The media fanned the memories of disbelief and horror we felt when those twin towers tumbled down... / I didn't know until last week that Sep 11 was the anniversary of another world-changing event. It wasn't much noted, maybe because it celebrated peace, and in this new century we honour violence. / Sep 11 was the $100^{\text {th }}$ anniversary of the day Gandhi asked Indians in Johannesburg to end British rule of India. It was to be done without violence (Satyagraha). / "There is no way to peace, peace is the way", ${ }^{4}$ were his message. How do you make transition from a culture of violence to a culture of peace? Bertrand Russell rightly mentioned "its coexistence or no existence". ${ }^{2}$ And the Biblical message "Everyone who hates his brother is s murderer". Similarly, consider his closeness to the Tao, which declares,"Weapons are instruments of fear. They are not a wise mans tools. Peace and justice are dear to his heart, and victory is cause for rejoicing". 
In many countries Communist and non-Communist, developed - the generation gap seems to be greater than ever, and a vast wave of protest and unrest on the part of students and other young people is challenging the existing political and social leadership and perhaps even the underlying political social canons and institutions or World Political System (WPS). As Walter Lippmann has pointed out, "the word revolution carries with it today a far deeper meaning than it did when many of us were young." Today revolution covers many faces Human Development Report, 2004 said, "embody the fundamental cum democratic values of human civilizations" 5 after Sherin Ebadi, become Winner of Nobel Peace Prize in 2003, it is continue, as Mohammed Yonus and his Grameen Bank become Winner in 2006. To the extent diversity of culture or tradition within distinct civilizations poses a problem of balancing the common and the unique, the preeminent way of resolving the problem and caring for the diversity of tradition. However, with increasing recognition of cultural liberty as a human right Edmund Burk defines, "Radical Reforms are the best form of traditions and legacy of politics in present and past. If there is no any radical reform then the development of societies will restrict and masses will remain unaware of progress."

\section{Different problems before the world:}

The present atmosphere in globe due to the policies, which executed by the rulers, includes ecology, economy, and social extremism. These (EES), are interrelated and going towards the potential catastrophic ecological breakdown through the standard economic models. As nature is the greatest obstacle of all to the future of the free-market system and cannot be treated as an adversary. There is a need of protection. Whether or not professional economists are truly blind to ecological problems they behave as if the less said about it the better. Perhaps they fear that revealing or analyzing this major contradiction of our economic system would be detrimental to its preservation while undermining the scientific pretensions of their discipline and the standing of their own profession. Whatever the limitations and mass denial of mainstream economics, it has become clear since the path-breaking work of Nicholas Georgescu-Roegen ${ }^{6}$ In the early 1970s (subsequently popularized by Professor Herman Daly and others) that economies must ultimately be analyzed in terms of actual or potential energy flows and entropy, or used up, non-available energy. In other words, the economy, like other physical systems (including the human body) must be understood within the framework of the Second Law of Thermodynamics. ${ }^{7}$ 
This law applies for the simple reason that our economic system is a subsystem of the natural world and does not encompass that world. To consider the economy as the encompassing system and nature as a mere sub-system and then to examine economic phenomena using a mechanistic epistemology (Georgescu-Roegen's term) is a purely artificial construct. The economic process is not an isolated, self-sustaining process. This process cannot go on without a continuous exchange, which alters the environment in a cumulative way, and without being, in its turn, influenced by these alterations.

Recognising this basic truth would involve recasting much of the academic cannon as presently handed down from one generation to the next, a task which occasions limited theoretical and practical enthusiasm. Scholars duty, however, is not to shield any profession but to describe the world as it is. To deny the enormous pressures placed upon nature by capitalist economies (and even more by formerly socialist ones) is something non-believable. Standard economic calculations treat the consumption of both renewable and non-renewable resources (natural capital) as income and as contribution to growth. Growth, in turn, is considered synonymous with economic well-being. Another thing, which must be taken into consideration, is free market whose future also depends on who receives the benefits of growth. That's why George Bernard Shaw said, "A government which robs Peter to pay Paul can always depends on the support of Paul". 8 If the rewards are aimed at the bottom half of the population; these relatively poor will use their money overwhelmingly for consumption and will keep demand buoyant. If the rewards go to the top of the social scale instead, the recipient will place ever-greater sums in financial markets rather than in goods and services. As a result, demand will fall, bringing with it the problems of rising inventories, over production and stagnation. The nature of income distribution is therefore crucial to the longer-term well being of the system.

Sharp social divisions and class struggle, as Marxists perhaps still call it, constitute a genuine menace. Beyond a certain threshold, disparities are problematic for the system and must be carefully monitored. The fact that great differences in wealth and living conditions can provoke rage, disruptive behaviour and violence is hardly news but the late twentieth century has added a new wrinkle to his age-old truth, the tendency of the information-rich to provoke the rage and violence of the information-poor. The information-poor are a globe-spanning category and may or may not be the same as the materially poor. Woodrow Wilson observed that high society is for those who have stopped working and no longer have anything important to do. Some rich societies like the United States, in spite of sharp class frictions, though the existence of thousands of selfcontained, walled and gated private communities reveals a profound 
apprehension. It is not clear how much longer this relative tranquility may continue, particularly when the middle classes can no longer count on social benefits once supplied without direct financial outlay, such as satisfactory public schools and safe neighborhoods.

In the European Union, although social extremes are less glaring, chronic unemployment, and stagnation of wages in the lower brackets and the prevalence of temporary jobs or sharp increases in the number of working poor cause resentment. The condition in rest of the globe is worse than the priors. Meanwhile, the western politicians invoke family values in the mistaken belief that these values may somehow serve to hold together societies undergoing increasing stress. Sir Ernest Benn quoted; "Politics is the art of looking for trouble, finding it whether it exists or not, diagnosing it incorrectly, and applying the wrong remedy." They do not explain how masses of people can adapt instantly to unemployment, inferior or precarious working conditions, geographical dislocation and longer hours while simultaneously devoting the requisite time and attention to their families. In most North American or European families, both parents now work in order to make ends meet. Thus the contribution of the family to social stability is also weakening. South - eastern England and some neighbourhoods of London are booming whereas much of the North is wasteland and other areas of the capital are in decay. The United States' rust belt stands in sharp contrast to more dynamic areas of the South and West. At the global scale, Tiger or Dragon Asia was typically regarded as a positive area. Africa qualifies as the quintessential loser.

The current existing systems of the world need itself a gross control. Eminent scientist explains that large interactive systems perpetually organize themselves to a critical state in which a minor event starts a chain reaction that can lead to a catastrophe. Self-organized criticality applies to both the natural and the economic spheres because the global system is a prototypical large interactive system. The timing of such a minor but critical, precipitating event is unpredictable; we have nonetheless entered the realm of the sooner or later. ${ }^{10} \mathrm{We}$ may place the critical state in the even broader context of what philosopher Paul Virilio has called the global accident. As he explains, the world, whatever its nature, embodies its own specific, inherent, virtual accident.

Thus the invention of the airplane implies the simultaneous invention of the crash; nuclear power means meltdown; the computer carries with it the possibilities of catastrophic information loss and fraud; stock markets and other fora of exchange or speculation eventually leads to bursting financial problems, and so on. Capitalism, to use its scientific name, is not the natural state of mankind. Rather, it is a product of cumulative human ingenuity, a social construct 
and as such, perhaps the most brilliant collective invention in all history. The topic Political Science and Beyond is like a fresh breath in the polluted atmosphere the topic is confronted with a crucial question; does the very success of this global invention imply that somewhere in the future lurks the global accident, the one from which the system of the world politics might not recover? We cannot answer this question, but points us to others to which it is our mandate to reply:

- $\quad$ Is the global system now protected?

- Are our present institutions sufficient to the task?

- Are our scholars and wisdom's ready to think beyond correctly?

- Are present political theories having capabilities for future challenges?

- Whether our global institutions developed beyond campus and across national borders?

We reply in the negative. The means so far devised for overseeing, safeguarding and perpetuating the system and the globalises policies are grossly inadequate. A brief inventory of existing global institutions shows that most of them are not so worthy for escaping the problems on the horizon. They should have productive for sense of security and adequate in their performances. If they fail that means, we live in a tragically under-managed world. To avoid the consequences we are facing, need of a healthy discussion of the concept known as Peace Science.

\section{Need of Peace Science:}

Initiatives: - We are present halfway through the decade for the promotion of culture of peace approved by the UN General Assembly in 1999. The last five decades have witnessed several significant advocacies for education for peace. UNESCO's recommendations on education for international understanding, peace, human rights and fundamental freedoms (1974) and UNESCO's 1994 action plan for education for peace, human rights and democracy, endorsed by 144 countries, are two of the prominent landmarks. UNESCO launched ASPnet in 1953 to promote international understanding and peace. Up to present the process had long achievements, but simultaneously the WPS showed different behaviour to overcome from the consequences we are facing, need of a healthy discussion of concept known as Peace Science.

In the formation of peace science, countries' experiences depends not only on politics but also on their economics, institutions, and policy responses, that is on governments' ability to gain agreement for through discourse, 
understand as both a set of ideas and an interactive process. We should show not only how matters discourse but also when it matters, that is, when it acts as a causal influence on peace, alternating perceptions of interests and over-coming institutional obstacles to change. It should demonstrate through the examination of matched sets of cases in which the presence of a coherent discourse contributed to the success of peace and its absence contributed to its failure. The sense of security can perform through a mighty concept that is the process of peace. For which Mahatma Gandhi said, "There is no way to peace, peace is the way".

The concept of peace starts with the concept of birth. Every effort must be exerted to protect, nurture, and sustain the living beings Life is most precious commodity and it begin in the mother's womb, one may say that peace or war emanates from the womb of a mother, at another occasion M. Gandhi states "If we are to teach real peace in the world we have to begin with children". ${ }^{11}$ Practice of peace must revolve and penetrate five layers of social units. Individual, family, community, nation and international community. They all inter-twine and relate with each other. In the individual sense, peace is a state of mind, which allows the individual to operate optimally. It can constructively contribute to the fashioning of its world. Some pre-conditions occur in this state. At first, absence of constraints affects mans freedom; include religious, political, economic, social, technological, and cultural factors. Then growth in body and mind, emotions, spirits, in isolation and communion with others.

This sense concern with mother's immediate health and nutrition for baby. If diet were good, then body would evolve into a sound physical structure, which develops sound mind, an emotion and behavior, the nourishment of mother leads global peace movement. Peace initiatives begin from family, which is nucleus of the society, the negative forces war, famine, disease, ignorance, and exploitation threats, the family nucleus but could not disturb its social image, within these confines the seeds of attitudes, values, traits, and psychosocial, emotional norms take shape, these values and goals cherished by generations.

Then children are exposed to community of families, these social structure, families are virtually bombarded with huge nets of social biases, political and vested interest, economic inequalities, religious rigidities and norms, culture patterns and propaganda, technologies. If children are loosely anchored to their families, and are left without guidance to this social atmosphere, then it initiates into confusion, hatred, self-pity and violence begins their trend. That results not only in the poverty of the third world but also in the affluence of first world cities. An alarming increase in drug-addiction, organized crime, street violence, and 
frauds. And the biggest one is scientific research and development on weapons for war and peace invasion, religious dogma, political party machination for power, economic elite and business monopolies, and cultural engineering. These are the more conspicuous and dramatic examples of societal ills that bread violence and tear the fabrics of peace. For these situations P. Nehru write in his Glimpses of world History, 'The chains which some times tie up our bodies are bad enough; but the invisible chains consisting of ideas and prejudices which tie up our minds are far worse. They are of our own making and tough often we not conscious of them, they holds us in their terrible grip.. ${ }^{12}$ And the UNESCO as the International Decade declared 2000-2010, for promotion of a culture of peace and nonviolence for children of the world, that brings us to the nations which are marked by their strength of vision and the histories comprise the have not's of third and fourth worlds, been able to break their bondage of poverty, ignorance and disease.

In fact, a large part of their misery and state of under-development stem from forces beyond their control, their former colonial masters and the superpowers obsessed with global control and dominance. And so we are witnessing today the phenomenon of techno-economic denomination where first world governments predominate the international free markets, the applications of science and technology to the cause of war and competitive advantage, the arming and finance of terrorist brigands, the drugs trafficking, and acts of violence pitting brothers against brothers, citizens against fellow citizens, the poor against poor. As a remedy to this Plato provides elaborate guidelines for the race, preserve numerical stability and ensure political equilibrium. Plato's instructions ensure that the upper classes - the brightest and best - will be given more opportunities to procreate than the lower orders. In the fifth century BC, morality was generally equal to or greater than fertility; war, disease and other accidents could wreak havoc and the leaders needed cunning to maintain the state at its ideal size with the optimum mix of inhabitants. To that end, says Socrates, the rulers will 'be obliged to make liberal use of lies and deceit for the good of the governed'. ${ }^{13}$

The state of affairs move towards, the international community. A stage of global movement for peace. UNESCO rightly mentioned, "Since war begins in the minds of men, it is in the minds of men that the defence of peace must be constructed". ${ }^{14}$ The governments like United States of America is inching towards the realization that peace is the best policy for global interest: that is positive environment for development of peace. Towards these goals, all international bodies (Governments, Corporate Sectors, and NGOs) frame their policies, projects and programs for movements toward peace, irrespective of competitive advantages of world resources, armaments stocks, and political and religious 
ideologies. Peace should be the byword and the endword for development. Although NGOs have been contributing to different aspects of peace viz. human rights, gender discrimination, environment etc, they do not impact adequately on basics; there is need for networking among all such institutions in order to enhance their effectiveness.

\section{Conclusion:}

All the system is covered by the deeds and way of thinking of the peoples; the situation in which we are living is well defined that the tied life and the grip of ideas leads us towards the grip of deeds, if we think on then can remove all the Apartheism, the Socio-Political health is a function of harmony. Thus the Old Testament describes, 'Behold, how good and how pleasant it is for brethren to dwell together in unity'.

\section{References}

1. Palmer and Perkins. (1985) International Relations: The World Community in Transition, (Preface), CBS Publishers \& Distributors, Delhi.

2. Fred Metcalf. (1986) The Penguin Dictionary of Modern Humorous Quotations, Penguin Books.

3. Motilal Sharma (2004) 'Role of University in Nurturing Peace Culture', University News 42(46): 173.

4. Diana French. (2006) Williams Lake Tribune, Canada.

5. Soumitra De. (2004) 'Multiculturalism and Indian University Education', University News 42(46): 55.

6. (1971) 'The Entropy Law and the Economic Process', Cambridge: Mass, Harvard University Press.

7. 'The entropy of a closed system increases with time' or heat cannot be transferred by any continuous, self-sustaining process from a colder to a hotter body'.

8. George Bernard Shaw. (1944) Everybody's Political What's What?.

9. Sir Ernest Benn. (1930) Quoted in the Observer.

10. Per Bak and Kan Chen. (1991) 'Self-Organised Critically', Scientific American 46-53.; also Per Bak. (1996) 'How Nature Works', Copemicus/Springer Verlag. 
11. National Curriculum Framework Review. (2005) 'A Draft', National Council of Education Research and Training [NCERT], New Delhi, p. 183.

12. Rafiq Zakaria. (1995) The Widening Divide, Viking Penguin Books India (P) Ltd, New Delhi.

13. Plato. The Republic, 459b et seq.

14. Preamble of the Constitution of UNESCO. 